\title{
Reconnecting with darkness: gloomy landscapes, lightless places
}

\author{
Tim Edensor
}

Department of Geography and Environmental Management, School of Science and Engineering, Manchester Metropolitan University, Chester Street, Manchester, M1 5GD, UK, t.edensor@mmu.ac.uk

This paper investigates the effects and affects of darkness, a condition that is progressively becoming less familiar for those of us in the over-illuminated West. In countering the prevailing cultural understanding that darkness is a negative condition, I draw attention to other historical and cultural ways of positively valuing darkness. Subsequently, in drawing on two sites, a gloomy landscape at a dark sky park in South Scotland, and a tourist attraction in which a simulation of New York is experienced in a completely dark environment, I explore the multivalent qualities of darkness. In foregrounding the becoming of sensory experience in gloomy space, I highlight the mobilisation of alternative modes of visual perception in as well as the emergence of non-visual apprehensions, and suggests that the potentialities of darkness might foster progressive forms of conviviality, communication and imagination

Key words: darkness, illumination, perception, sensation, landscape, space 
Miroslaw Balka's How it is, installed in the Turbine Hall at London's Tate Modern Gallery, in 2009, made quite an impact. A huge, container-like metal box, with one end open, facing away from the entrance, and inside walls lined with light-absorbing black velvet, both enthralled and troubled visitors. Walking towards the unseen end of the box, visitors became progressively cloaked in a deep darkness. Symbolic allusions abounded as visitors and reviewers tried to make sense of the work, which for some, connoted the rail trucks that conveyed victims of Nazi genocide to concentration camps or the suffocating containers that transport illegal migrants to Europe from the East. Yet it seemed that in the moment of encounter, the overpowering affects and sensations of the inner environment subsequently overwhelmed representational thinking. In the absence of light, other sensations of tactility, sound and smell were foregrounded, provoking an enhanced awareness of the velvety textures of the wall lining, the footsteps and breathing of other visitors, and the scents of perfume and body odour.

The mobilisation of these non-visual senses was necessary to avoid the social discomfort of bumping into others. Though one's eyes gradually made out murky shapes in the gloom, and any rising fear could be swiftly allayed by turning back towards the opening, walking in thick darkness seemed unnerving for some, as sighs and spoken fears made evident, whereas for others, myself included, the very darkness seemed exciting, alluring and mysterious. I contend that both kinds of response were provoked by the absence of darkness in everyday life and its deep unfamiliarity for most people, but also the profound ambivalence that has long surrounded darkness.

In this paper, by way of addressing the paucity of studies of the geography of the night, I reconsider the relationship between humans and darkness. As John 
Jakle notes, 'landscape has been conceptualised primarily in terms of daytime use' (2001: vii). Despite the fact that all earthly space is illuminated or dark for much of the time, theories almost invariably focus upon that which is perceived during daylight. Yet, the landscape at night, with its illuminated and dark areas, possesses divergent qualities and is apprehended in very different ways to the daylit landscape. In an era in which extensive illumination has made the experience of darkness rare throughout the West, I will counter the negative qualities associated with darkness by foregrounding sites in which darkness is being revalued. Throughout most of history illumination has been partial and limited yet in modern times, the experience of the night is now rarely shaped by the experience of deep darkness. This prevalent historical darkness has, as Koslofsky points out, inspired multivalent conceptions ranging from a 'diabolical night, nocturnal devotion, honest labour at night, and a night of drunken excess and indiscipline' (2011: 5). Overwhelmingly, however, for centuries dominant conceptions of darkness have been associated with the primitive, evil and dangerous. I contend that these negative associations are increasingly questioned, particularly in the context of the over-illumination that blights much Western nocturnal space, a condition with which darkness contrasts.

I firstly outline these persistent negative understandings but also alternative accounts that foreground more positive qualities that are associated with gloom. I then explore how the apprehension of dark spaces and landscapes might be understood. Given the lack of academic studies upon which to draw, the discussion subsequently focuses upon autoethnographic accounts of visits to two very different sites associated with darkness, though these subjective impressions are interwoven with other accounts that focus on the sensory apprehension of gloom. The relationship between darkness and landscape, and the sensory experience of a 
landscape devoid of artificial light, is substantively explored through a commentary of a visit to the Galloway Forest Dark Sky Park in South Scotland, a site whose designation has emerged from the Dark Sky movement which campaigns for a decrease in illumination so as to foster a richer encounter with the starry nocturnal sky. To further bring out the complex feelings provoked by darkness in place, I investigate a tourist attraction in New York at which a total absence of light is critically used to interrogate the experience of the city and how this may be altered in the dark where vision is nonexistent. These accounts endeavour to revalue those attributes of darkness that have been sidelined in the quest for bright space: the potential for conviviality and intimacy to be fostered in the dark, the aesthetics and atmospherics of darkness and shadow, the affective power of the star-saturated sky, the possibilities for looking at the world otherwise and apprehending it through other senses.

\section{Dark in times past and present: continuing fears and desires}

Even though modern illumination has transformed nocturnal urban experience, producing spaces of regulation, hierarchical selectiveness, consumption, fantasy and imagination, darkness continues to be largely negatively conceptualised in the west. We persist in referring to the 'dark side' and the 'forces of darkness' to connote the devilish, qualities that contrast with the advent of light cast by God out of preceding darkness, Christian allusions that remain deeply embedded in western thought and feeling. Though we no longer refer to Africa as the 'Dark Continent' in contradistinction to the enlightened West, we continue to cite a 'heart of darkness' to denote the most depraved actions perpetrated by humans, and we describe that vague historical period imagined to contrast with the illuminating modernity of scientific, rational thought as the 'Dark Ages'. We continue to refer to 'dark deeds' or 
'dark thoughts', to the 'shadowlands' in which supernatural forces lurk, to being 'kept in the dark' as a metaphor for a state of ignorance, and we take a 'shot' or 'leap' in the dark when we engage with unseen and unknown risk.

Besides resonating with religious metaphors, these metaphors no doubt testify to earlier conditions in which perils of all sorts lurked across spaces of pervasive gloom. Craig Koslofsky (2011) points to the associations of darkness throughout the $17^{\text {th }}$ and $18^{\text {th }}$ centuries with witchcraft, devilry, heresy, sin and death, as the devout struggled through 'the long night of the soul', their faith threatened by temptation and terror. Superstition and fear of the devil pervaded common understandings and the powers of numerous fabulous and malign entities, the evil spirits and disciples of Satan, the demons, imps, goblins, ghouls, boggarts, elves, witches and other supernatural beings magnified in the dark night. The idea that the dead inhabited a light-less world was widespread. Such notions associated with the darkness of night persist, and popular culture remains haunted by mythical creatures such as vampires, werewolves and zombies that relate to more contemporary concerns.

These longstanding fears also have origins in the very real perils that pervaded a pre-illuminated world after nightfall. In towns and cities, rubbish, ditches full of excrement and overhanging timbers were unseen dangers, and in rural areas 'fallen trees, thick underbrush, steep hillsides and open trenches' (Ekirch, 2005: 123) posed hazards. Lanterns or lamps might guide those who ventured into the dark but they were liable to expire or be blown out by the wind. In the absence of light, it was difficult to distinguish between friends and foes. The dark night was the domain of other, more human perils, the footpads, burglars and arsonists, and the later increase in violent gangs and criminals in the early modern city provided further 
reason to stay indoors. Householders securely bolted doors to prevent intrusion and many larger towns organised a watch, a defensive group who guarded against fire and interlopers, as well as locking the town gates after sundown. The effort to keep darkness at bay with candles and rushlights was ongoing, and even these light sources only illuminated that which was nearby. Fears about robbers and rapists persist, adding to the supernatural and occult myths that foster nyctophobia.

I suggest that encountering darkness contains residual intimations of this preindustrial life as a realm in which bad things lurk in the shadows, where you can get lost, an oneiric realm of insubstantial and indeterminate forms. By contrast, Christians continue to conceive God as the light-bringer and Christ as the 'light of the world'. This religious imagery has transmuted into scientific discourse, with light serving as a metaphor for 'truth, purity, revelation and knowledge' (Bille and Sørensen, 2007: 272), and signifying the enlightenment ideals of rational exploration and objectivity through which 'the pall of gloom which prevents the full visibility of things, men and truths' may be banished (Foucault, 1980: 153). In addition, the centrality of light to vision is implicit in the evolution of modern ways of seeing. These prominently included a disciplinary gaze through which power was mobilised and circulated across illuminated and daylit space, and romantic practices of gazing upon and subsequently representing the extraordinary - notably 'picturesque' and 'sublime' landscapes (Urry and Larsen, 2012) where the play of sunlight was a key aspect through which such qualities were discerned.

These practical and metaphorical appraisals of light are underpinned by the widespread imperative to banish darkness with the advent of electric lighting, synonymous with the industrial age and producing 'a new landscape of modernity' (Nasaw, 1999: 8). Illumination has opened up the night to extensive, more diverse 
space-making social practices and freer movement as the previously gloomy nightscape that coerced most people into a shuttered existence after sundown has largely disappeared. Chris Otter is right to assert that the development of lighting technologies reveals an uneven history of 'multiple, overlapping perceptual patterns and practices rather than singular paradigms', typified by improvisation, local politics and competing technological systems (2008: 10). Nevertheless, the broad shift to extensive artificial illumination has progressively opened up ever more spaces for nocturnal use, intensifying the glare of light into multiple hitherto unlit realms. Integral to the emergence of 'bourgeois sensibility' and liberal modes of governance, lighting has formed part of an overarching mission to eradicate garbage, dirt, disease, noise and gloom through the development of clean water, policed public spaces and improved public health. Accordingly, darkness has been gradually 'transformed from primordial presence to a more manageable aspect of life' (Koslofsky, 2011: 278).

Crucially though, the terrors associated with darkness have never been culturally and historically universal but have been variously supplemented by economic and practical imperatives, alternative pursuits and desires that construe darkness more positively. For despite bureaucratic, scientific and urban planning injunctions to banish darkness, creating 'new centres of power and new margins of exclusion' (ibid: 280), often oriented around gender and class, there have always been those who find succour, opportunity, excitement and refuge in the dark. As illumination has expanded across space, it has been resisted and utilised by 'the traditional inhabitants of the night: servants, apprentices and students... tavern visitors, prostitutes' and other workers and pleasure-seekers (ibid: 278).

The seeking out of darkness however, did not emerge with the advent of urban illumination, as Veronica Della Dora shows with regard to the gloomy caves 
sought by early ascetic Eastern Christians. Rather than offering the sensual plenitude and visual revelation offered by views from mountain peaks, the cave served as a site of prayer and retreat in which the lack of vision promoted apophatic religious intimations. For these denizens, '(V)isual presence conceals spiritual absence; visual absence invites divine presence' (2011: 762). Similarly, Koslofsky draws attention to how the growth of a confessional, mystical theology in later medieval and early modern times promoted an apophatic sense of devotion in the dark, a condition valued as conducive to profundity and beauty, and the acquisition of divine knowledge expressed by an acknowledgement of the ineffability and inexpressibility of God. Yet such desires for the crepuscular were not circumscribed by religion, for as Chet Raymo (2008) explains, in the bardic schools of ancient Ireland, young poets were sent to cells containing nothing but a bed, and enclosed in total darkness. An environment free of visual distractions, it was believed, offered the most fertile conditions in which to compose poetry.

In medieval Europe, night was usually divided into first and second sleep, where after a first sleep of a few hours, people would awaken during the dark hours, and besides completing household tasks, might converse, tell stories, share intimacy or spend time thinking before their second sleep. Other secular, prosaic values were expressed by the poorer classes who could escape the surveillance of domineering masters under cover of darkness, and by political activists who gained 'freedom from both labour and social scrutiny' (Ekirch, 2005: 227). Indeed, in more modern times, Roger Palmer conceives of the night as similarly ripe for transgression, the 'time for daylight's dispossessed - the deviant, the dissident, the different' (2000: 16-17) to engage in oppositional activities and for pleasure-seekers to escape the strictures of commerce, economic rationality and spatial regulation maintained during daylight. In 
the dark, they may carve out time and space, replacing these dominant imperatives with 'sensualities and sociabilities, aesthetics and the art of resistance' (ibid: 453). In the nocturnal city, usually in conditions of shadow and gloom, musicians ply their trade and bohemians and urban explorers reclaim a space replete with a multitude of promises as well as abjection and exploitation, as sex workers and drug dealers minister to particular nocturnal desires.

Despite the expansion of illumination into most spaces, the modern city also contained a host of new dark realms, the tunnels, cellars and sewers imagined as specific sites of danger and desire, as well as the theatres, cinemas, photographic darkrooms, ghosts trains and later on, black-box galleries in art venues (Elcott, 2012). Thus though illumination has contributed to the modern production of a 'technological uncanny' through the transformation of the city into spectacle, the production of a phantasmagoric realm, the radiant city also has its contrastingly stygian realms in which we may experience 'the shadowy hauntings of the fleeting and insubstantial' (Collins and Jervis, 2008: 1). Darkness then, the unlit elements that we cannot perceive, contributes to the illusory qualities of this oneiric illuminated city, 'exhilarating and disorienting to its inhabitants' (McQuire, 2008: 122), in which distances are difficult to ascertain, illuminated buildings appear to float in a sea of darkness and large swathes of space are impregnable to sense-making. This phantasmagorical light and dark city has been represented in fantastic chiaroscuro of film noir, the lurid night-time photography of Alfred Steiglitz and the charged canvases of Edward Hopper, cultural forms that collectively foster the production of a realm of fears and enticements, a city that is simultaneously 'a snare, a canvas, a foreign land, a fantasy, a stage' (Sharpe, 2008: 7). 
The appreciation of gloom is also manifest in the Danish practice of creating hygge in interior spaces, an atmosphere of cosiness and conviviality through the judicious use of candles and firelight (Bille and Sørensen, 2007). Beyond the west, other practices conceive shadow and darkness in positive ways as well. Most famously Junichiro Tanizaki's (2001) exquisite account of the virtues of shadows in generating mystery, subtle aesthetics and reverie serves as a counterblast against the impact of extensive illumination, conceived by Tanizaki as a Western intrusion, on the Japanese experience of place. In Taoism, the darkness retreat fosters the central value of indiscernibility. An individual may spend up several weeks in a completely darkened room, a meditative setting in which participants are induced into a state of relaxation as the eyes recuperate from visual over-stimulation, and the usual attention on ordinary schedules and responsibilities is suspended. After some time, it is claimed, images may appear in the dark and dreams become particularly lucid (Universal Tao). On the other hand, in Rural India, the dearth of illumination is often conceived as synonymous with underdevelopment and productive of danger, signifying poverty and a lack of mobility (Kumar, 2012).

Despite certain positive conceptions and uses of darkness, it is evident that in the west, the broadly negative conceptualisation of dark persists. Taking issue with the binary of darkness and light insofar as they play across space, Gallan and Gibson (2011) point to the shifting cultural and historical meanings that I have identified. They argue that the peddling of normative dualisms is liable to facilitate conservative and authoritarian practices of control through establishing curfews, intensifying surveillance and promoting particular religious, commercial and moral values. Alternatively, they suggest, this historical evidence emphasizes the benefits of darkness, which might accordingly be reconsidered as 'a conduit for new forms of 
conviviality and camaraderie' (2011: 2514). With this is mind, I now further investigate the perceptual capacities and impediments engendered by the affordances of darkness.

\section{Apprehending dark space}

In order to address how we experience darkness, an interdisciplinary approach that also draws on biology, phenomenology and geography as well as social practices and cultural history is required, for responses to gloom are formed in the situated spatial, historical, physical, sensual and epistemological encounter with shifting forms and variants of dark space.

Though the visual has been afforded prominence in landscape as object and viewer as subject, recent (post)phenomenological accounts have emphasised the landscape as animated and foregrounded multisensual apprehension. As with all spatial experience, the meaning and apprehension of dark space unfold relationally, underlining, as Rose and Wylie insist, that landscape constitutes 'the materialities and sensibilities with which act and sense' (2006: 478). We do not behold a passive, inert scene but are immersed in a pulsing space, in the currents and energies of a world-in-formation, even in the darkness, and the light or lack of it is entwined with our sensing bodies, blurring distinctions between outside and inside. Critiques of accounts that have privileged the visual point to the non-visual ways in which space is apprehended through the senses of hearing, smell, touch and proprioception, which may supplant vision as the most dominant sense at particular moments and be entangled with seeing. More nuanced understanding of visual perception and the landscape it co-produces go beyond the consumption of the objectified spectacle, and account for the multisensual qualities of looking, the ways in which it is often 
intertwined with sound and touch (Degen, DeSilvey and Rose, 2008). Further, as William Connolly insists, 'visual perception 'involves a complex mixing... of language, affect, feeling, touch and anticipation' (2011: 46). These entanglements through which we become attuned to landscape, provide an array of resources through which we respond to changing conditions, such as darkness, with which we may open ourselves up or with which we may shrink.

Nevertheless, the apprehension of darkness is conditioned by the propensities of the human eye to discern aspects of place and landscape in little or no light, as well as the position of the head at the top of the body with its two eyes looking forward as it moves through space. Light - a form of electromagnetic radiation - is detected by the human sense of sight via frontally situated eyes. Vision is facilitated when the eye's convex lens focuses light to produce an inverted image of a scene on the retina, which is then sent via the optic nerve to the brain to process this information. However, the light-sensitive receptors on the retina are of two kinds, cones and rods, which respond to different wavelengths of light and consequently produce two different forms of vision. While the cones function as the eye adapts to normal levels of (day)light, allowing the experience of a colour spectrum, the rods operate when there are low levels of light. The rods thus shape the human visual apprehension of darkness, making the eyes more sensitive to light, shape and movement but impairing the ability to discern colour. Moreover, during the daylight, human vision generally scans when encountering a landscape: the eye 'does not look at things but roams among them, finding a way through rather than aiming for a fixed target' (Ingold, 2011: 132). Yet, as I will show, in the darkness, the sight of small patches of light in an otherwise dark landscape, or the contrastingly bright 
stars and moon in the sky, may serve to focus vision far more acutely than in the daylight where a multitude of competing potential sights deter orientation towards such focal points. The eye takes around 20 minutes to become attuned to darkness, after it has operated in illuminated surroundings. Accordingly, because we usually perceive space under contemporary conditions of pervasive illumination, the eye takes longer to become acclimatised to darkness and thus the efficacy of human night vision is weakened.

In the visual perception of space, Alphonso Lingis identifies the ways in which a changing range of 'levels' of light that are shaped by the depth of field and brightness, continuously play across space, extending 'an expanse in which things can be seen' and with which we continuously adjust (1998: 26). Thus, we may be drawn to a particular colour, patch of light or shade as shifting patterns of light and dark engender continuous (re)attunement. Accordingly, being in and of the landscape involves different modes of looking within shifting fields of varying depth gazing upon vistas, attending to obstacles, glazing over in distraction, scrutinising matters close at hand, as scenes unfold incessantly, as light levels shift and bodies attune. According to Greenlaw (2006), a complex, subtle and ever-changing patterns of light and dark across British landscapes contrasts with the fierce interplay of shadow and glare in more southern realms. In British spaces, the world takes shape under conditions of cloudiness, mild shadows and weak suns to produce a distinctive tonal atmosphere and mode of apprehending and representing landscape.

Accordingly, as Morris emphasises, darkness is 'situated, partial and relational' (2011: 316), as the examples featured in this paper emphasise. Accordingly, the experience of darkness might be best understood as an ongoing 
flow, where the body's rhythms and those of the earth, sun and moon, the variable levels, intensities and qualities of light, the affordances and features of the landscape (especially as the body moves through it) and the shifting moods, mindful thoughts and imagination course through timespace. Where gloom descends, modes of looking shift as the varying levels and qualities of dark and light facilitate or restrict movement, focus attention on particular elements in the landscape both near and far, motivate or restrict the body's movement, and shape the emotional and affective response to space. Where there are lower levels of light there is a diminution of colour, as the landscape devolves into a pared down palette of blacks and greys in which other colours can no longer tincture surrounding space, 'radiate presence, projecting their qualities outwards and colouring the environs' (Thibaud, 2011: 211).

A focus on light and dark also reveals how conceptions of landscape usually exclude the celestial, instead, focusing upon that which is of the earth, the landforms, contours and configurations, geomorphologies, natural histories, cultural inscriptions and distinctive features of particular kinds of terra firma. By contrast, elements such as light, dark, sunsets, wind, rain, clouds and fog have been ontologically conceived as the immaterial opposite of the concrete, material earthliness of the land, around and above which they swirl and float. Tim Ingold refutes the distinction between material earthliness and the immaterial, celestial qualities of landscape, for together they constitute a fluid and emergent indivisible field. Thus the land is not 'an interface' separating earth and sky but is a 'vaguely defined zone of admixture and intermingling' (Ingold, 2011: 119) in which medium and substance blend, as they do also in the human body. To see and not see the sky is to see a light or a darkness that continuously enfolds and is enfolded into the world and provides the means 
through which we perceive it, contributing to the light or darkness that constitutes the experience of inhabiting the visible world, through its glare, gloom, colour and intensity.

To focus solely on these physical capacities and the entanglement of the perceiving body and the landscape, however, is to sideline how perception of the landscape is shaped by cultures of looking. Hannah Macpherson reinforces Connolly's assertion that 'seeing involves movement, intention, memory, and imagination' (1049: 2009) but highlights how these elements shape attunement. Accordingly, in present times, becoming attuned to darkness is unfamiliar for many because of the continuing negative associations and dominant visual practices I have discussed and the absence of darkness in most everyday spaces. Widespread knowledge of the regular patterns in the star-filled sky used to guide the way for travellers. Moreover, familiarity with the phases of the moon meant that in apprehending the nocturnal landscape, including the ways in which moonlight transforms landscape, 'changing colours and contours in its shape-shifting light... there existed a variety of possibilities, some too subtle for our modern eye to appreciate' (Attlee, 2011: 5). Now, however, according to David Nye, the ability to perceive the night sky and to see in the dark is curtailed since most people 'know only an artificial darkness that is fogged with electric light' with the sky 'a smudged and meaningless background' (2010: 9). This hints at an emergent dissatisfaction with the over-illumination that saturates most space, with the exception only of 'the great deserts and oceans (that) offer large areas of darkness' (Attlee, 2011: 3), as most of us are 'condemned to simmer in our own electric boullabaise' (ibid: 9), marginalising qualities of mystery and beauty, and limiting opportunities for intimacy 
and self-reflection. Massive expenditure of energy is deployed to keep cities illuminated throughout the night and besides its effects on humans, the impact of pervasive illumination can severely affect the perceptual capacities of non-humans. The rhythms of bird and insect migration are disturbed, fireflies cannot transmit their signals, and though moths are drawn to light, excessive illumination banishes them to darker realms. Migrating sea-turtles become disorientated and the navigation of beetles by moonlight becomes confused The movements of salamanders towards ponds to breed is disrupted, song birds are killed by flying into illuminated buildings, and cows milk production might be interrupted.

\section{Experiencing dark landscape: Galloway Forest Dark Sky Park}

In order to investigate the experience of a completely unilluminated landscape and by way of foregrounding this unfamiliarity, I now provide an account of a visit to Glen Trool in Britain's first dark sky park in Southern Scotland. Galloway Forest Dark Sky Park, and others such as Exmoor and Sark in the UK, Hungary's Zselic National Landscape Protection Area, and Flagstaff and the mountains of Hawaii in the USA, have been inspired by a desire to create nocturnal landscapes that are not dominated by artificial lighting, or what is termed 'light pollution'. They seek to reinstate the experience of darkness. The Campaign for Dark Skies points to an aesthetic loss as well as to the environmental, social, health and economic problems produced by poor and excessive electric illumination, identified according to five criteria that define 'light trespass', 'light clutter', 'over-illumination', 'glare' (where contrast between dark and light is great) and 'skyglow'. While the first four generally occur in urban areas, skyglow has become so extensive that it pervades areas far from cities, deterring the attempts of astronomers to gaze upon nocturnal skies. The 300 square mile Galloway forest, containing the darkest skies in Europe, rates a 3 
(out of 9) on the Bortle scale (which measures night sky darkness based on the observability of astronomical objects). To maintain this condition of dimness, measures to reduce skyglow, light trespass, and glare include the shading of all light installations, lighting curfews and strategic tree planting.

Never having visited Glen Trool before, its unfamiliarity was compounded by my experiencing the valley in the dark, on the night of the $21^{\text {st }}$ of September, 2012. It was a very clear night with no cloud cover and a thin crescent moon that disappeared from the sky after 10pm. As night fell, the evening patchwork of grey landforms gave way to a more homogeneous, dark gathering of largely featureless earthly elements that contrasted with the constant play of light above. This epitomised John Daniel's contention that daylight vision 'catches on the surface of things, gets snagged and tugged about by their multiplicity' whereas looking at trees in a forest, the sensation is of their 'commonality' and 'not the names I knew them by but their essential namelessness' (2008: 23). This dense intertwining of earthly matter was only disrupted when a form suddenly became apparent, such as the separate silhouette of a single pine or oak tree against the sky.

The light in the moonless night sky does not suffuse the land with warmth like the sun or cast shadows like the moon but produces an uncanny sense that sustains the aforementioned overemphasis on the distinction between 'solid ground' and the celestial. In the forest, given the dearth of available visual information cast by celestial light on the earthly elements of the landscape when the crescent moon had descended below the horizon, vision was drawn towards the sky. The subject is swathed in darkness, like the landscape, and cannot distinguish him or herself from it visually. By daylight, foreground and background co-exist in the field of vision, and the eye continuously shifts between them as the body moves through the landscape. 
But under conditions of ddarkness, like fog, we are left to 'to ponder our conditional engagements with the near and far' (Martin, 2011: 455). By daylight, the depth of the landscape is readily apprehended with reference to the horizon, 'a mediating device that offers a form of visual calibration through the perceivable distance or depth between self and horizon' (ibid: 460), as a succession of scenes fade into the distance towards the horizon where detail ceases. In the dark, the horizon simply marks the boundary between earth and sky, enclosing a dark, largely undifferentiated realm that thwarts the usual sense that the landscape broadens out from the observer. In Galloway, our attention thus focused primarily on the sky.

The night sky changes with the variable patterns of stars and the changing levels of light bestowed by the falling and rising sun, and on other evenings this dynamism would be characterised by variations in cloud cover, the shifting clarity of the atmosphere and the phases of the moon. The sky thus dominated the landscape in a way it rarely does during daylight, and in the relative darkness of the forest park, this attracts astronomers to gaze upon distant galaxies, as it does where tourists seek the aurora borealis in more northerly climes (Edensor, 2011). Walking through Glen Trool from $10.30 \mathrm{pm}$ with one companion, and no sign of any other people, the absence of skyglow produced optimum conditions for gazing upon the constellations, including an evident Milky Way, now an unfamiliar sight in most of the UK

The infinite, dispassionate play of innumerable stars and galaxies was somewhat overwhelming and a source of wonderment, especially given their unfamiliarity to me because of the impossibility of witnessing a night sky such as this in most areas of the UK. Astonishingly, this concentration upon the skies was dramatically intensified by the appearance of a fantastic, mysterious sequence of 
slow moving, very bright lights that were astounding to behold in a landscape such as this. All attention focused on this incomprehensible sight, later revealed to have been a meteor or space junk entering the earth's atmosphere and burning up, and unbeknown to us at the time, the subject of widespread alarm and fascination across the UK (BBC News, 22/09/12).

Despite the overwhelmingly dynamic sky that diverted concentration away from the ground, we gradually become conscious of the shifting availability of light according to the qualities of the surrounding and covering elements in the landscape, as well as the reflective qualities of particular elements. Although at first it was difficult to discern anything distinctive, our eyes slowly become attuned to the different levels of light that emerged. In other contexts, Attlee discusses how moonlight does not reveal the hidden in the landscape but transforms it, 'changing colours and contours in its shape-shifting light' (2011: 5) and in more wintry realms, a covering of snow may stand out in an otherwise featureless landscape, reflecting light, whereas other photo-absorbing features cannot. As we walked through Glen Trool, more obscure glimmerings were faintly apparent, including the wet surfaces of rocks, the silvery slivers of streams and the smooth white surfaces of silver birch trees, although darker shapes would also suddenly loom out of the dimness. Yet these variations on black and grey could not enchant and spread through the landscape as could the vibrant colours of daylight. More crucially, the path, laid with light-coloured shale, was visible for a few feet, though where tree cover occurred, it became impossible to discern, necessitating the use of a torch. Without this artificial light, movement seemed perilous, but its use had the effect of revealing particular elements close at hand. The architecture of a pine tree in its monochrome shapeliness stood out against the blackness, bringing forth an appreciation of form 
that would not be gained in daylight because of the plethora of other visual elements in a landscape, and thereby revealing the visual affordances of darkness as a backdrop.

There seemed to be no other people in Glen Trool but from seemingly far away, though how far was impossible to guess in the absence of other visual information, another visitor's presence was revealed by a thin torchlight. This weak light heralded this presence far more acutely in the absence of any other artificial light than would have been the case by daylight, when in all likelihood the visitor would not have been perceptible. Yet though this presence was amplified by the torchlight, there could have been several other people in the glen who were not using torches and therefore could not be perceived at all. Wylie insists that as seeing subjects we are always intertwined with a consciousness that we can always be seen as part of the 'landscape of visible things' (2007: 152), as an observable as well as observing subject. Similarly, Connolly discusses Merleau-Ponty's insistence that the perception of depth in the landscape is achieved by prior experience of space from multiple perspectives, an anticipatory disposition that also conjures up the sense that we can be seen from multiple perspectives, in contemporary times often as an object of surveillance. However, in the dark, our presence may not be perceptible at all, raising perhaps, sensations that we can hide or act as we wish in the absence of the constraining gaze of others, but also worries that should an accident befall us, nobody will see us. Similarly, the imperceptible presence of others may be both pleasing and alarming.

To see in and with the dark is to see otherwise, to apprehend space as an entity that lacks the complex configurations sensed by day, to not see certain features of the landscape at all, but to see others vividly. Not only that, but where 
gloom thickens, the boundaries of the body become indistinct, merging with the surroundings and providing an expansive sense of the space beyond us as we become one with the darkness. These 'modalities of vision' make impossible the omniscient gaze of the separate being detached from the landscape, mobilising a visual expertise that classifies the characteristics of spaces and places. Instead, vision in the gloom might, as Otter contends, 'have less to do with power than with emotional and affective experience' (2008: 5), with levels of light and dark provoking affective and emotional resonances, cajoling bodies into movement, activating passions, instigating sensual pleasures and discomforts.

In addition to the reconfiguring of visual experience, a crucial aspect of apprehending landscape by dark is that because it is harder to judge depth and distance, with many details obscure and colours largely absent, we draw on the nonvisual senses of touch, smell, hearing and proprioception to move through and experience space. The experience of landscape that connects the perceiving body to an expansive darkness can instigate sensations of being tethered to the earth by gravity, temperature, the stillness and freshness of the air, a delicate array of sounds, and the shifting textures underfoot, as well as a conjectural and imaginative approach to space that moves beyond the scanning gaze practised in daylight. For instance, according to Robert MacFarlane, in the dark 'one becomes more aware of landscape as a medley of effects. A mingling of geology, memory, nature, movement', in which landforms 'exist as presences: inferred, less substantial but more powerful for it' (2005: 75). With specific reference to a mountain landscape, he contends, we might become aware that we walk 'through the depths of time as well as physical space' as human and geological history press upon the walker, whose imagination 'curls around the landscape, sensing its shapes and intuiting the forces 
which have brought it into being: ice, fire and water' with 'incredible slowness and unimaginable force' (ibid, 76).

In discussing the dominance of visual apprehension of the landscape, John Tallmadge asserts that in daylight, the "ubiquity and pervasiveness of light make everything stand out in hard-edged clarity. We can read things at a distance and make our plans'. However, he contends that vision 'allows us to know things only by their surfaces' (ibid: 142). Tallmadge discusses how he 'could fix a position, identify a person or animal moving across a slope, trace a route' in the daylight, but by night 'identification took longer and I had to suspend judgement while gathering information from other senses', using hearing, touch and smell, a process that 'required more patience and intimacy than sight'. He contends that in becoming attuned to the landscape through these other senses, the body 'relaxes, opens, breathes, extends its attention outward into the world the way a plant feels its way into the soil with roots or into the air with leaves' (2008: 140).

In Glen Trool, this is exemplified by how the route was negotiated in darkness, for the path meandered, descending and ascending frequently. Because it could only be recognized a few feet ahead or not at all when under the shadow of trees, the anticipation of what movements to make had to occur moment to moment, with no sensory information about what would happen. The body could thus not prepare for a steep ascent or vertiginous descent but had to operate in the here and now. This curiously made the journey less tiring, for mental engagement with the act of walking relies on this somatic expectancy, the body bracing itself for the effort of walking upwards or downwards. This uncertainly also called upon an intercorporeal experience, with I and my companion debating how to progress along this dark route: 'This bit is steep!', 'What's that there?', 'Careful, the path is over here', 'Look 
out, there may be a drop'. At these moments, as with the partially sighted and blind hillwalkers discussed by MacPherson, 'residual sight tended to be concentrated on navigation and safety...walking became a practice more analogous to an adventure sport than a contemplative stroll' (MacPherson, 2009:1048). While the path we followed had been shaped to offer scenic experience of the glen, to stimulate the romantic gaze, we could not enact such a visual practice.

Though visual perception improved with gradual optical attunement, other senses were heightened by the lack of visual information and other, often ignored vital elements in the landscape became prominent. For instance, although the environment at first seemed rather silent, sounds gradually impressed themselves on the sensing body. Most obviously, in the absence of wind, the ever changing sounds of flowing water accompanied every step. What must have been a distant waterfall formed an ever-present background noise, changing in its tones as the direction and volume of water modified and the sound arrived from different directions as we walked onwards. This was augmented by the regular gurglings of small cataracts and burns, which changed in intensity and pitch as they were approached and passed. Sonically, a sense of depth was restored to the landscape. The occasional rustle in the grass or flight from the trees heralded the presence of other animals, made especially evident when a tawny owl spent a minute or so shrieking, leaving a sonic vacuum that compounded the ensuing silence. When my companion's torch was switched off, his attendance could only be discerned by the noises he made while speaking breathing or moving, unless he was close at hand, in which case the warmth and tactility of his body revealed his presence. Feet quickly learned to identify the different textures underfoot, such as where tree roots burst out of the ground to make the path uneven or muddy sections made it slippery, and this 
sensory awareness was advanced by the sound made by our own footsteps, the most prevalent noise. In addition, strong smells of pinesap, fungi and carrion attracted our sensory attention, as well as other unidentifiable earthy scents. As the walk progressed, the shifting quality of the air marked progress through different kinds of space; the mild breeze that assailed the face when in open ground and the contrasting stillness in the midst of a group of trees. The breeze, the owl, the water and comet demonstrated the vitalism of the landscape at night, dispelling the initial illusion of quiescence, though this is also attributable to the inability of the human sensorium to detect countless other movements and processes that co-produce the becoming of the world.

The perceptual experience of Glen Trool in the dark is perhaps best captured through the metaphor of flow. We became detached and attached to points in the landscape, sometimes lost our bearings, focused on finding the way, became absorbed in the atmosphere, tuned in to sounds, sights and smells, tried to make things out, and were occasionally subsumed by a powerful impression such as the owl's shrieking and the uncanny lights. Much of the time, the landscape and its elements were vague and imperceptible, yet this engendered continuous conjecture through which we made connections with landscape. Martin asks how one might respond to a pervasive fog: 'to immerse oneself? Or to struggle to locate position, to value distance?' (Martin, 2011: 456). In Glen Trool, both modalities were mobilised in seeking the barely visible signs that marked location and distance, and paying attention to the close at hand, but also becoming absorbed in the becoming darkness of the landscape. 
In walking through this dark landscape, it was also possible to imagine movement through space in a pre-electric age, where a greater range of sensory skill and knowledge was required. As I have already stated, when dark was an everyday feature of life, knowledge of the movements of the moon and stars facilitated orientation. Similarly, where a person had to navigate in the dark, they became keenly aware of sounds and smells to identify spatial configurations and familiar sites, as well as developing a heightened tactile sense of place, often facilitated by making notches in surfaces. Inhabitants might practise echolocation, using handclaps and shouts in landscapes made strange by darkness, and the distinctive surfaces and gradients walked upon became recognizable through enhanced tactile sense. Indeed, children's games were devised to inculcate regular exposure to darkness, developing a predilection to locate place by touch and a familiarity with local landmarks and hazards (Ekirch, 2005).

\section{Dialogue in the Dark: Sightless in New York}

In order to deepen this investigation into the ambivalence of darkness, the constraints and opportunities it fosters, and its prompting of a range of sensory apprehensions and impressions, I return to an autoethnographic approach in examining an internal space in which total darkness is the key feature that shapes their appeal and guides their rationale.

Situated in the popular tourist complex of South Street Seaport, and housed in the same building as Gunther van Hagen's notorious Bodies exhibition, Dialogue in the Dark is a unique visitor attraction that has the avowed aim of providing an insight into the ways in which the blind and partially sighted apprehend New York City. 
Devised by Andreas Heinecke to encourage visitors to abandon usual patterns of perception and thought, the attraction aims to promote a multisensory experience that also facilitates empathy and communication with the blind and partially sighted 'without hindrances of insecurity, pity or prejudice'. It is one of seventeen similar current exhibitions worldwide (Dialogue in the Dark, 2012). Dialogue in the Dark consists of a walking journey through five simulated venues in Manhattan. Though the attraction is educational in its attempt to convey the experience of blindness, as sighted people, because we had prior experience of the two specific sites - Central Park and Times Square - and also of the three generic sites - a supermarket, a subway station and train, and a coffee shop - we could not but draw upon these memories in imagining and anticipating the appearance of the sites as we moved through complete darkness, working to make sense of space.

At the start of the experience, visitors are provided with a walking cane, and then requested to sit in a small chamber, in which to become accustomed to the absence of illumination as the lights slowly dim in transition to total darkness. Subsequently, as visitors expectantly sit in the dark, a blind or partially sighted guide verbally greets them, explains the attraction's mission and provides some ground rules, intimating that the inevitable physical contact should not be repetitively greeted with an apology. Valerie, our guide, requested that we follow the sound of her voice and use the stick to locate ourselves. This cane is used to mark out the concrete winding path and immediately induces a sense of tactility as information from the end of the stick is conveyed to the hand and brain. Though at first an unfamiliar manouevre that requires us to sense the world prioprioceptively through this extension to the body, the feel of the path via the cane comes to constitute a 
comforting material presence that also foregrounds an enhanced sense of the quality of concrete.

The first locale to which the path leads, 'Central Park', is replete with sounds of water, birdsong and other people in conversation or movement, and visitors are asked to place their hands in the 'fountain' and feel the foliage and flowers. Memories of the site are drawn upon to try to pin down the site in the imagination but the sensations of flowing water, temperature and texture are far more powerfully immersive in the absence of vision and inculcate an appreciation of the non-visual dimensions of the park. Similarly, the sounds of people convey a sense of happy conviviality and pleasure as a multitude of New Yorkers and tourists take their pleasure in Manhattan's vast green swathe, foregrounding the sociality of the setting. The sense of touch once more comes to the fore in the adjoining 'supermarket', where visitors are requested to handle commodities in order to identify them. With loose items of fruit and vegetables, touch proves more acute than might be imagined, as a marrow, a lemon and an aubergine are readily recognisable, but its inadequacy in recognizing the contents of serialised cans and boxes also becomes apparent, bringing forth the sensory homogeneity brought about by standardisation of products of all kinds into identical units.

The next experience involves a simplified simulation of catching the subway train, and this is particularly revealing of the difficulties produced by a lack of sight and the progressive attunement that is required to negotiate such space. Here we are asked to walk down the steps into the subway - of course, there would be many more in reality - and orient ourselves on the platform to the doors of the train. It seems almost impossible that in a far more complex space, such manoeuvres could be undertaken and the steering presence of the guide is essential. As Devlieger and 
Strickfaden maintain, the actual experience of underground travel for blind people is complex, for trains create 'considerable noise, movement of air', and stations 'can be very large, with few points of reference' and do 'not change much with varying natural light or temperature'. Moreover, because great numbers of people use the stations for short periods, there are minimal opportunities for extended social interactions (2012: 229-30).

This difficulty in making sense of and navigating space in the absence of vision is exacerbated when we alight from the train and ascend into a simulation of Times Square. Here, the smells and sounds of this frenetically busy place compose a multisensual blitz that wholly overwhelms and disorients the senses. This calls to mind Simmel's (1995) observations on the city as it was in an in earlier modern era, where he depicts urbanites as compelled to develop a blasé attitude to insulate themselves against an unaccustomed sensory onslaught. The welter of sounds produced the most disorienting and least pleasant experience of the tour, being a dense racket that produced an impression of chaos, a paralysing soundscape that overwhelmed attempts to gain any sense of place in the dark. However, Valerie informed us that the unsighted are gradually able to distinguish between sounds, their distance and their provenance, though this was difficult to imagine for the inexperienced. In addition, the encounter with Times Square also foregrounded aspects of the environment highly pertinent to the blind and partially sighted; the material and sensual cues that encourage them to accomplish tasks and negotiate space. We focused upon the textures of the pavement that heralded a crossing point and the chirping birdsong that signified when it was time to cross the road. To end the tour, we were ushered into an ersatz café, sitting down amidst the pervasive smell of coffee, and the lights gradually come on to reveal the guide. 
It must be emphasised that though the cane provides a basic tool for orientation, movement was primarily engendered by the vocal and physical guidance offered by our guide, Valerie. The injunction to refrain from apology draws attention to the different intimacies and forms of communication that are fostered in the dark. The tone and accent of voice, the gentle care inherent in the necessary chaperoning through unfamiliar space, the continuous physical closeness and the feel of breath and body heat, all loomed large and generated a precious sense of connection. A communion between guide and visitor was produced in which an encouraging, warm voice guided passage through space and transcended any visual appearance. With its inflexions and encouragements, this voice engendered the intimacy that supported the necessary trust that had to be placed in the guide. It also interrogated the imperialism of the visual as we attempted to guess the provenance of textures, smell and sounds to attain a mindful appreciation of these non-visual qualities.

I argue that we did not experience the attraction as would a blind person, though we were certainly persuaded to empathise with that condition as an alternative sensory apprehension of the world was advanced. I have already mentioned that we were able to imagine the spaces that we were moving through and sensing because we had previously experienced these iconic and generic places visually. A sense of place was thus conjured up by the sounds, smells and textures and augmented by a fluid imaginary that drew on this visual memory, and where specific memory was unable to recall a particular fountain, supermarket aisle or subway station, one was invariably conjured up in the mind's eye. For those with vision, darkness solicits such an imaginary, exemplifying MacPherson's claim that 'the process of seeing is dependent not only on the physical organ of sight but also on memory and imagination' (2009: 1049), and Connolly's contention that perception 
'not only has multiple layers of intersensory memory folded into it, it is suffused with anticipation' which allows for adaptation to conditions (2011: 48, also see Edensor, 2012). We thus engaged in continuous visual conjecture in this dark realm.

Moreover, tthough most of the journey was spent in what seemed like the total absence of light, on a couple of occasions the faint glow of the outline of a door could be discerned as our eyes strained to find something recognisable. In this sense, we might distinguish the experience from that of the blind person by recognising that we always scan for the perceptible where we can see nothing, and also always have the expectation that the darkness will end. We thus see the dark as a homogeneous black entity when plunged into it that may be subject to change.

\section{Conclusion}

This paper has adopted a largely autoethnographic approach at two sites at which I have endeavoured to develop a more nuanced conception of the dark. I have argued that darkness has persistently been negatively conceived, based understandably on the perils of a pre-illuminated era but also articulated through religious conceptions and enlightenment values. This has been furthered by the enormous spread of illumination across space for commercial and practical reasons, but also as part of a broader bourgeois project to encourage 'proper' modes of perceiving and sensing the world, informed by values of clarity, transparency and romantic aesthetics. This highlights how the sensing of space is culturally shaped by the ways in which the powerful inculcate the prioritising of particular modes of apprehension and the values associated with specific sensations. The regulatory process through which darkness 
has been banished, I contend, has reduced the complexity and variety of the ways in which humans sense nocturnal space.

Despite this ordering of the night via extensive illumination, I have also emphasized that through time and space there have always been those who have sought darkness, inspired by a range of political, religious, practical, artistic and hedonistic desires. In these pursuits we can discern alternative cultural values and sensations associated with gloom. Thus while I have acknowledged the perils and constraints of operating in dark space, I have focused on how it might be conversely considered to offer an alternative experience of landscape and place, and this resonates with the resurgence of desires to become reacquainted with the dark. As mentioned, there are several other dark sky parks and tourist attractions organised around the simulated production of dark cities across the globe. There are also the often euphoric responses to the unfamiliar conditions created by urban blackouts (Nye, 2010). In addition, the restaurants which offer meals served exclusively in the dark (Dans le Noir?), the concerts staged in the dark by Malian blind musical duo, Amadou and Mariam, the growing popularity of dark retreats, and the global event 'Earth Hour', organised by the World Wildlife Fund, during which cities simultaneously switch off swathes of no-essential lighting for one hour to raise awareness of climate change (Earth Hour).

For me, the gloomy setting of Galloway Dark Sky Park stimulated alternative modes of sensing space to those employed by daylight, and this fostered appreciation of other qualities in the landscape. Visual apprehension focused upon objects not usually foregrounded in the daylight, pre-eminently the sky and horizon, but also the clusters of dark shadow, the occasional singular slihouette of a tree, and the surfaces of brightly hued and watery elements. A sense of depth was difficult to 
attain, though was recovered though a heightened attunement to sound, exemplifying how when vision failed, other olfactory, auditory and tactile senses came to the fore, enriching the encounter with space and affording a different way of sensing the vitalism of landscape. The potential for surveillant scrutiny that permeates much contemporary space was denied by an inability to be seen, a condition replete with ambivalence, along with the inability to perceive others. These apprehensions also brought to mind the unreliable qualities of clarity and transparency in the visually beheld landscape, especially for creatures of limited visual capacities. An inability to identify and classify elements in the dark landscape, however, called for imagination and conjecture. According to Ingold, imagination should not be conceived as some sort of fake illusion but as 'a way of living creatively in a world that is itself crescent, always in formation... to participate from within, through perception and action, in the very becoming of things' (Ingold: 2012: 3). This world that is continually coming into being is entangled the perceiving subject, entwining sensory data, memory and embodied imagination in an ongoing making sense of the world. Darkness is part of this flux and becoming, continually disperses and re-emerges with diurnal and seasonal patterns and climatic and other events

At Dialogue in the Dark, in the complete darkness, there was a more enforced focus on tactile, proprioceptive, textural, sonic and olfactory senses, more acutely revealing how the non-visual qualities of space are so frequently eclipsed or dulled by the primacy of the visual. The recognisable shape and texture of certain things rendered them identifiable and the sonic qualities of place were profoundly, even overwhelmingly evident. Yet in the absence of vision, an imaginative envisioning of place in the mind's eye, based on prior experience and conjecture, even more fully 
underlines Ingold's argument about the integral role of imagination in the unfolding becoming of place. Furthermore, a necessary focus on the quality of our guide's voice and her accompanying tactile presence fostered a rich sense of convivial intimacy. Yet while providing an insight into the potential of these other senses to enrich spatial experience and social interaction, I do not intend to minimise how in certain respects, the lack of vision in the dark constrains the knowledge of space and the efficacy of social intercourse.

My aim here however, has been to celebrate the unheralded virtues of darkness. I have shown how the affects generated by the coalescence of dark, temperature, silence and closeness to others penetrate the body, enfolding it into the field (Brennan, 2004). This potency is perhaps intensified in a world in which deep darkness is unfamiliar. As Pallasmaa asserts, darkness can 'dim the sharpness of vision, make depth and distance ambiguous, and invite unconscious peripheral vision and tactile fantasy' (2005: 46), and it may also inculcate a sense of mystery, profundity and speculation, in which the process of trying to see and feel your way through space gives rise to unfamiliar, unbidden thoughts and sensations. Darkness offers opportunities to dream, mull over, remember and worry. Dark space also offers possibilities for developing more intimate, convivial and focused forms of communication, unhindered by multiple visual distractions that sidetrack conversation and story-telling. Connolly (2011) discusses how a Foucauldian disciplining of the senses shapes a cultural disposition to look in particular ways, to respond and feel and make sense of the seen. An encounter with darkness can challenge these habitual affective and sensual anticipatory dispositions, providing relief from trying to discern the world through vision and interrogating the illusory 
promises that looking can reveal all, as the overlooked emerges via other sensations.

Such potentialities are likely to eventuate since there seems little doubt that the excessive illumination of contemporary cities will fade into less intense lighting in the future, on the grounds of sustainability, and a reconfigured encounter with darkness will become more familiar than it is today (Edensor, 2013. As a familiar way of being in the world, dwelling within darkness and gloom may become a condition which will be 'familiar, sensible, and intelligible (Vannini et al, 2012: 368), generating a habituated mode of perceiving space that echoes with the spatial experiences of times past.

\section{Acknowledgements}

Grateful thanks to my companion on these visits, the wonderful Kim Kothari

\section{References}

Attlee, J. (2011) Nocturne: A Journey in Search of Moonlight. London: Hamish Hamilton

BBC News, 22/09/12 "Meteors" sighted in skies across UK, BBC News website: http://www.bbc.co.uk/news/uk-19683687

Bille, M. and Sørensen, T. (2007) An anthropology of luminosity: the agency of light, Journal of Material Culture 12(3): 263-284

Brennan, T. (2004) The Transmission of Affect. Ithaca: Cornell University Press

The Campaign for Dark Skies http://www.britastro.org/dark-skies/guidelines.html?00 (accessed 10/10/11)

Collins. J. and Jervis, J. (2008) Introduction in Collins, J. and Jervis, J. (eds) Uncanny Modernity: Cultural Theories, Modern Anxieties. Basingstoke: Palgrave

Connolly, W. (2011) A World of Becoming, London: Duke 
Daniel, J. (2008) In praise of darkness, in Bogard, P. (ed) Let There Be Night: Testimony on Behalf of the Dark. Reno: University of Nevada Press.

Dans le Noir?: http://www.danslenoir.com/london/ (accessed 18/10/11)

Degen, M, DeSilvey, C and Rose, G (2008) Experiencing visualities in designed urban environments: learning from Milton Keynes, Environment and Planning $A$ 40(8): 1901-1920

Della Dora, V. (2011) Anti-landscapes: caves and apophasis in the Christian east, Environment and Planning D: Society and Space 29: 761- 779

Dialogue in the Dark (2012) Programme, New York: Premier Exhibitions Inc.

Devlieger, P. and Strickfaden, M. (2012) 'Reversing the $\{\mathrm{im}\}$ material sense of a nonplace: the impact of blindness on the Brussels Metro', Space and Culture 15(3): 224-238

Earth Hour http://www.earthhour.org/Homepage.aspx (accessed 10/10/11)

Edensor, T. (2011) Aurora landscapes: the affects of light and dark, in Benediktsson, K. and Lund, K. (eds) Conversations with Landscape, Aldershot: Ashgate

Edensor, T. (2012) Illuminated atmospheres: anticipating and reproducing the flow of affective experience in Blackpool Environment and Planning D: Society and Space

Edensor, T. (2013) 'The gloomy city: rethinking the relation between light and dark' Urban Studies

Ekirch, R. (2005) At Day’s Close: Night in Times Past. London: W.W.Norton and Company

Elcott, N. (2012) In search of lost space: Stan Douglas's archaeology of cinematic darkness, October Winter: 129: 151-182

Foucault, M. (1980) Power/Knowledge: Selected Interviews and Other Writings, 1972-1977. New York: Vintage.

Gallan, B. and Gibson, C. (2011) Commentary: new dawn or new dusk? Beyond the binary of night and day, Environment and Planning $A$ (forthcoming)

Greenlaw, L. (2006) Between the Ears: The Darkest Place in England. BBC Radio 3, (25/3/ 06)

Ingold, T. (2011) Being Alive: Essays on Movement, Knowledge and Description. London: Routledge

Ingold, T. (2012) Introduction, in M.Janowski and T.Ingold (eds) Imagining Landscape: Past, Present and Future, Aldershot: Ashgate

Jakle, J. (2001) City Lights: Illuminating the American Night, Baltimore: Johns Hopkins University Press

Koslofsky, C. (2011) Evening's Empire: A History of Night in Early Modern Europe. Cambridge: Cambridge University Press 
Kumar, A. (2012) Stories of Light: http://www.storiesoflights.com/ (accessed 19/01/13)

Lingis, A. (1998) Foreign Bodies. Bloomington, In: Indiana University press

MacFarlane, R. (2005) The via negativa, in Farquhar, A. (ed) The Storr: Unfolding Landscape. Edinburgh: Luath Press, pp 73-78

McQuire, S. (2008) The Media City: Media, Architecture and Urban Spaces. London: Sage

Macpherson, H. (2009) The intercorporeal emergence of landscape: negotiating sight, Environment and Planning A 41: 1042-1054

Martin, C. (2011) Fog-bound: aerial space and the elemental entanglements of bodywith-world, Environment and Planning D: Society and Space 29: 454-468

Morris, N. (2011) Night walking: darkness and sensory perception in a night-time landscape installation, Cultural Geographies 18(3) 315 -342

Nasaw, D. (1999) Going Out: The Rise and Fall of Public Amusements, Boston: Harvard University Press.

Nye, D. (2010) When the Lights Went Out: A History of Blackouts in America. MIT Press: Cambridge, Massachussets

Otter, C. (2008) The Victorian Eye: A Political History of Light and Vision in Britain, 1800-1910. Chicago: University of Chicago Press

Pallaasma, J. (2005) The Eyes of the Skin: Architecture and the Senses. London: Wiley

Palmer, B. (2000) Cultures of Darkness: Night Travels in the Histories of Transgression: From Medieval to Modern. New York: Monthly Review Press.

Raymo, C. (2008) Why the night sky is dark, in Bogard, P. (ed) Let There Be Night: Testimony on Behalf of the Dark. Reno: University of Nevada Press.

Rose, M. and Wylie, J. (2006) Animating landscape, Environment and Planning D: Society and Space 24: 475-479

Sharpe, W. (2008) New York Nocturne: The City after Dark in Literature, Painting and Photography, 1850-1950. Princeton: Princeton University Press

Simmel, G. (1995) The metropolis and mental life, in P. Kasinitz (ed) Metropolis: Centre and Symbol of Our Times, London: Macmillan.

Tallmadge, J. (2008) Night vision, in P.Bogard (ed) Let There Be Night: Testimony on Behalf of the Dark. Reno: University of Nevada Press.

Tanizaki, J. (2001) In Prasie of Shadows, London: Vintage Classics.

Thibaud J-P (2011) The sensory fabric of urban ambiances, The Senses and Society 6(2): 203-215 
Universal Tao: Preparation for Dark Room Retreat: http://www.universaltao.com/dark room/preparation.html (accessed 10/01/13)

Urry,J. and Larsen, J. (2012) The Tourist Gaze 3.0, London: Sage

Vannini, P., Waskul, D., Gottschalk, S. and Ellis-Newstead, T. Making sense of the weather: dwelling and weathering on Canada's Rain Coast Space and Culture 15(4) $361-380$

Wylie, J. (2006) Depths and folds: on landscape and the gazing subject, in Environment and Planning D: Society and Space 24: 537-554 